ORIGINAL ARTICLE

\title{
Use of nasal continuous positive airway pressure during neonatal transfers
}

R K Bomont, I U Cheema

See end of article for authors' affiliations

.....................

Correspondence to: Dr Cheema, Acute Neonatal Transport Service, Box 224, Addenbrookes Hospital, Hills Road, Cambridge CB2 2QQ, UK; irfan cheema@addenbrookes. nhs.uk

Accepted

17 September 2005

Published online first 4 October 2005

\begin{abstract}
Objective: To review all cases in which nasal continuous positive airway pressure (CPAP) was used as a means of respiratory support during land based ambulance transfers by a regional neonatal transport service.

Design: Retrospective study based on review of transport records.

Results: A total of 1175 transfer requests were received over the 21 month period. The infant in 163 of these cases was receiving nasal CPAP. Ninety two referrals were accepted by the doctor/nurse practitioner led team. Of these, 84 were transported while receiving nasal CPAP. Intervention during transport was required in three of these cases. Fifty five referrals were accepted by the nurse led team. Of these, 16 were transported while receiving nasal CPAP. Intervention was required in two cases.

Conclusion: There is a small but significant demand for transferring infants who are receiving nasal CPAP. Nasal CPAP appears to be a safe method of respiratory support for a carefully selected group of infants during land based ambulance transfers.
\end{abstract}

$\mathrm{N}$ asal continuous positive airway pressure (CPAP) is a widely accepted means of respiratory support for both preterm and term infants. It is increasingly used for a variety of indications, including support during acute and recovery phases of respiratory distress syndrome. A considerable body of evidence has accumulated over the last 35 years that supports its use in neonatal intensive care units. ${ }^{1-3}$ There is, however, limited literature on its use during transport. Data from adult patients suggest that a carefully selected group could benefit from a trial of nasal CPAP during transport to hospital. ${ }^{4}$ Limited literature from the neonatal population suggests that, although it is technically feasible to use nasal CPAP during transport, in the absence of further studies, it should be used with caution. ${ }^{5}{ }^{6}$ There are no data on the type of infants suitable for transfer while receiving $\mathrm{CPAP}$, the expertise required of the team undertaking the transfer, or the safety of such transfers.

In practice, this dearth of data has not proven too problematic because the typical newborn infants requiring inter-hospital transfer have often not been suitable candidates for nasal CPAP, as the severity of their illness usually merited intubation and ventilation for their journey to the admitting hospital. Historically, by the time these patients were considered stable enough to return to their local hospital, they had been weaned off nasal CPAP.

The recommendations for the reconfiguration of neonatal services $^{7}$ and the ensuing development of clinical networks are likely to have an impact on the number and type of infants transferred. The concept of managed care networks encourages early transfer to designated centres for intensive care or specialist services and return transfers for continuing care once intensive support is no longer needed. The shortage of intensive care capacity ${ }^{8}$ means that infants transferred to regional units will need to be transferred back to their local hospital as soon as possible to allow the cot to be used again. Many of these infants will be receiving high dependency care, including nasal CPAP. Reintubation and ventilation of all these infants for the sake of a safe journey is clearly not in the infant's best interest. It is therefore imperative that those responsible for transporting infants receiving nasal CPAP scrutinise this practice and share its results. Over time, such data may enable development of criteria for selecting infants to be transferred while receiving nasal CPAP, as well as standards for staff and the equipment used for such transfers.

The Acute Neonatal Transport Service provides day time (0800-2200) neonatal transport cover to the East of England, a region with more than 60000 deliveries per annum where 18 hospitals provide various levels of neonatal intensive care. The service has been in operation since July 2003. It comprises a cot bureau, dedicated transport nurses, advanced nurse practitioners, specialist registrars, and a consultant neonatologist. The transport nurses, advanced nurse practitioners, and specialist registrars are experienced in neonatal intensive care and receive specific and ongoing training in the transport of patients. All members of the team have current NLS certification. The transport nurses are not specifically trained in endotracheal intubation, but have skills that allow them to perform basic airway management, including the use of oropharyngeal airways.

Two teams are available: a nurse practitioner/doctor led team for emergency transfers and a nurse led team to carry out routine/repatriation transfers.

\section{METHODS}

All transfer requests made to the cot bureau for infants requiring nasal CPAP at the time of referral were identified from the database for the period 1 July 2003 to 31 March 2005. Figure 1 illustrates the referral and call triage process.

Criteria for selecting infants suitable for nurse led transfers were based around the criteria of the British Association of Perinatal Medicine for high dependency care.

Nurse led transfers are not available for the following group of babies:

- Intensive care babies (British Association of Perinatal Medicine 2001)

- Babies below $1 \mathrm{~kg}$ in weight

- Babies below 28 weeks gestation and less than 48 hours of age 


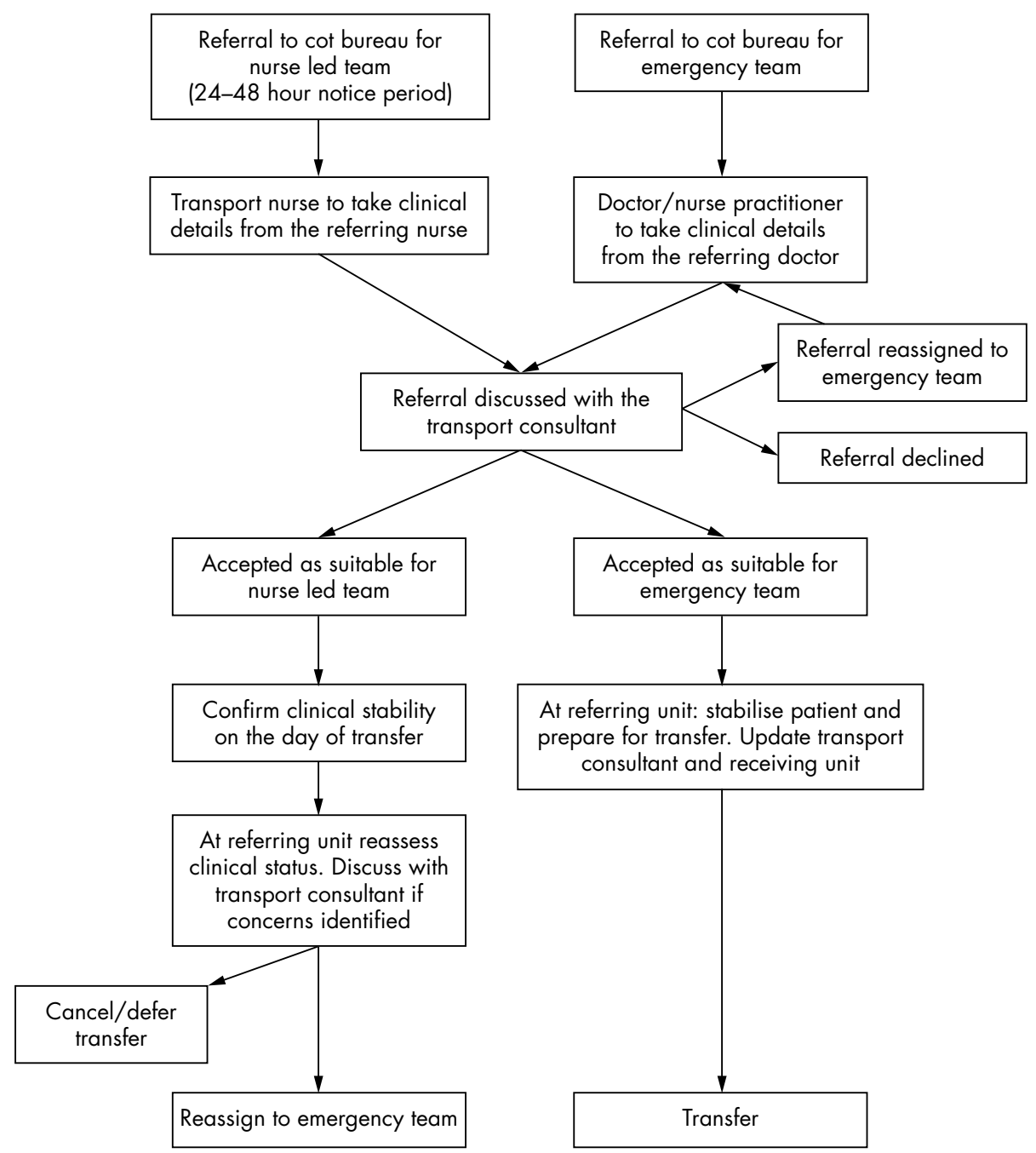

Figure 1 Referral and call triage process for transfer requests for infants requiring nasal continuous positive airway pressure.

- Babies receiving nasal CPAP for less than two days after extubation from a period of ventilation

- Unstable high dependency babies

- Babies with complex cardiac problems or those that require drugs to maintain duct dependent lesions

- Babies with complex surgical problems

- Babies with neurological problems that require constant monitoring and treatment to maintain stability

- Babies referred for intervention as a day case-for example, treatment for retinopathy of prematurity or airway examination

Nurse led transfers can be undertaken for the following patient groups:

- Stable special care babies

- High dependency babies who have been stable for 48 hours with no increasing oxygen requirement and no significant bradycardia or desaturation

- Babies receiving nasal CPAP who have been stable for 48 hours on this treatment with no increase in oxygen or flow, who have not had recent significant bradycardia or desaturation

- Babies referred for surgery who are stable for transfer and do not require interventions to maintain stability
- Babies with neurological disorders who have been stable for 48 hours

- Babies who have been extubated for 24 hours after being electively intubated for surgery and were stable before intervention

- Stable babies requiring outpatient appointment (not intervention) where the wait for the appointment does not exceed one hour

If the infant failed to meet these criteria, referring hospitals were advised of the need to delay the transfer until the infant was more stable. In cases where transfers were considered essential by the referring units on the grounds of family circumstances or the need to release local intensive care capacity, the transfer was reassigned to the emergency team. Duration of transport was also a consideration. Anticipated journey times of more than two hours led to exclusion from nurse led transfer.

Transfers were only accepted by the nurse led team after discussion with the transport consultant, with the explicit understanding that it was subject to a reassessment of the infant by the transport nurse on arrival at the referring hospital. If there were any clinical concerns about the infant's stability at that stage, the transfer would be deferred or cancelled.

When triaging infants receiving nasal CPAP to be transferred by the emergency team, the nature and severity 


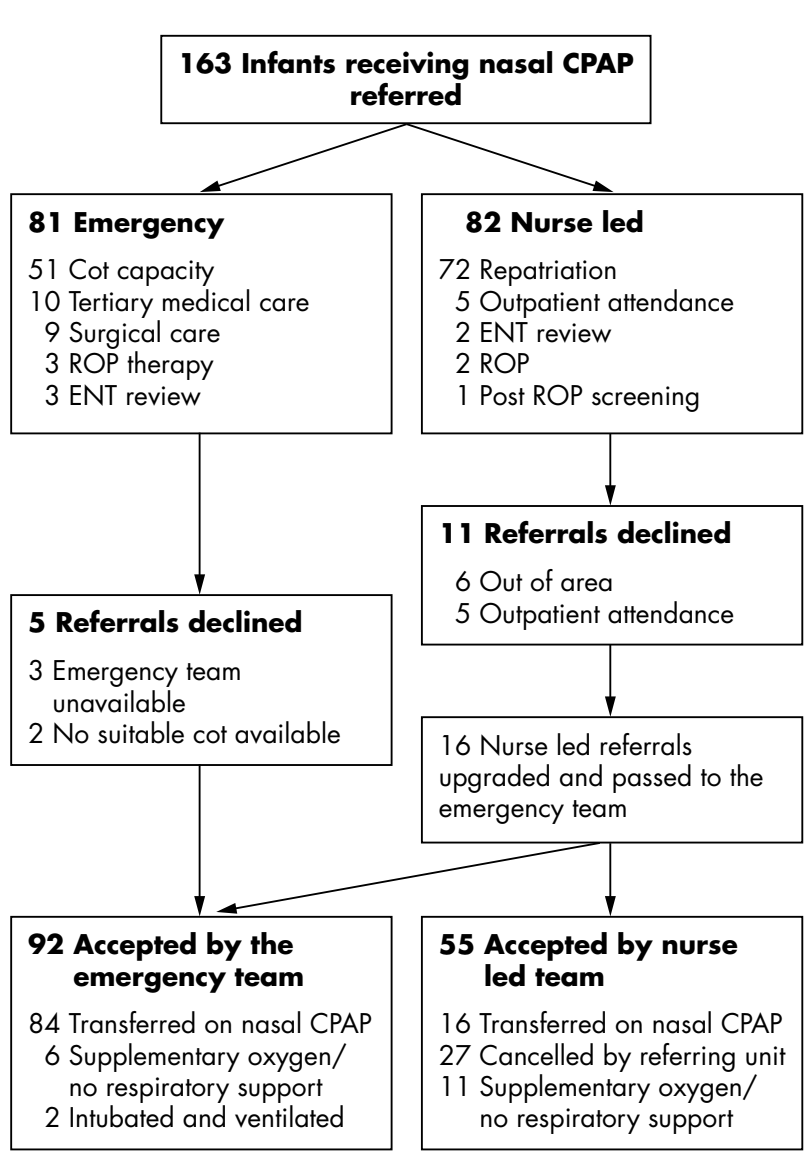

Figure 2 Triage of the 163 infants referred for transfer who were receiving nasal continuous positive airway pressure (CPAP). ROP, Retinopathy of prematurity; ENT, ear, nose, and throat.

of the illness and recent respiratory status including blood gas results were carefully considered. A provisional decision was then taken with regard to the appropriateness of the continued use of nasal CPAP. For example, infants with a poorly predictable or rapidly evolving disease process such as seen in the acute phase of infant respiratory distress syndrome, worsening respiratory status or borderline respiratory failure would be deemed unsuitable, and the referring unit was advised to intubate and ventilate the infant while awaiting the arrival of the transport team. In cases where infants were deemed stable on nasal CPAP, the transport team reassessed the infant on arriving at the referring unit. The decision whether or not to proceed with nasal CPAP was then made after discussion with the transport consultant present at the transport team's base. At that point, discussion also occurred with the receiving unit to update them on the infant's status and to ensure their continued ability to accept the referral.
Clinical information, including the mode of respiratory support at the time of referral, was prospectively documented and entered into an electronic database. Clinical observations, including temperature, heart rate, respiratory rate, oxygen saturations, and fractional inspired oxygen concentration, were documented every 15 minutes during the journey.

The dedicated neonatal ambulances carry 2720 litres of air and 4600 litres of oxygen which, at a gas flow of 8 litres/min during CPAP mode, allows a journey duration of up to 15 hours. Transfers were carried out using Dräger 5400 transport incubators (Dräger Medical UK Limited, Hemel Hempstead, Hertfordshire, UK). The integral Babylog 2000 ventilator was used to generate CPAP. Binasal Argyle prongs (Sherwood Medical Company, St Louis, Missouri, USA) were used for CPAP delivery. Nasal CPAP delivery was interrupted only very briefly when the infant was transferred to the transport CPAP system. The transition occurred mostly while the infant remained nursed in the static incubator. When this was not feasible, CPAP was continued during the period of transition by face mask and the Neopuff Infant Resuscitator (Fisher Paykel Healthcare Limited, Auckland, New Zealand).

\section{RESULTS}

Total referrals to the transport team during the study period were 1175 . The infant in 163 of these cases (13.8\%) was receiving nasal CPAP at the time of referral (fig 2). Eighty one infants were referred to the emergency team. The reasons for referral are shown (fig 2). Sixteen additional infants, initially referred to the nurse led team, were considered not to fulfil the nurse led criteria after call triage, and were reassigned to the emergency team, bringing the total referrals to 97. Five referrals were declined. Ninety two infants requiring nasal CPAP were therefore accepted by the emergency team. Eighty four infants were transported while receiving nasal CPAP (table 1).

The mean (SE) duration of the journey was 62.7 (2.9) minutes (range 24-150).

Three infants were identified at triage as being less than 34 weeks gestation and less than 72 hours old and as such were at risk of evolving infant respiratory distress syndrome. Two required CPAP intermittently at referral, had normal blood gas analyses, and no clinical signs of respiratory distress. These were transferred while receiving nasal CPAP. The third infant was electively intubated and ventilated by the transport team before transfer.

Intervention was required in three cases during transport (table 2).

Two infants were intubated and ventilated before transfer (table 3).

Six infants were transferred with no respiratory support or receiving supplementary oxygen from nasal cannulae.

Eighty two infants were referred for the nurse led transfer team. Figure 2 shows the reasons for referral. Eleven referrals were declined. Sixteen were considered high risk and reassigned to the emergency team after call triage. Of the

\begin{tabular}{|c|c|c|c|c|c|}
\hline & $\begin{array}{l}\text { Age at transfer } \\
\text { (days) }\end{array}$ & $\begin{array}{l}\text { Current } \\
\text { completed } \\
\text { weeks of } \\
\text { gestation }\end{array}$ & $\begin{array}{l}\text { Current } \\
\text { weight } \\
\text { (kg) }\end{array}$ & $\begin{array}{l}\mathrm{pH} \text { at } \\
\text { referral }\end{array}$ & $\begin{array}{l}\mathrm{PaCO}_{2} \text { at } \\
\text { referral }\end{array}$ \\
\hline Mean & 28.3 & 32 & 1.56 & 7.34 & 6.5 \\
\hline Range & $0-100$ & $27-41$ & $0.6-5.0$ & $7.24-7.47$ & $4.0-11.9$ \\
\hline SD & 24.3 & 1.1 & 0.9 & 0.05 & 1.5 \\
\hline
\end{tabular}


Table 2 Characteristics of infants transferred by the emergency team who required intervention during transfer

\begin{tabular}{|c|c|c|c|c|c|c|c|c|c|}
\hline Sex & $\begin{array}{l}\text { Postnatal } \\
\text { age } \\
\text { (days) }\end{array}$ & $\begin{array}{l}\text { Corrected } \\
\text { gestation } \\
\text { (weeks) }\end{array}$ & $\begin{array}{l}\text { Current } \\
\text { weight } \\
\text { (kg) }\end{array}$ & $\begin{array}{l}\text { Capillary } \\
\text { pH }\end{array}$ & $\begin{array}{l}\text { Capillary } \\
\mathrm{PaCO}_{2}\end{array}$ & $\begin{array}{l}\text { CPAP } \\
\left(\mathrm{cm} \mathrm{H}_{2} \mathrm{O}\right)\end{array}$ & $\mathrm{FlO}_{2}$ & $\begin{array}{l}\text { Duration of } \\
\text { transfer (min) }\end{array}$ & $\begin{array}{l}\text { Intervention } \\
\text { required }\end{array}$ \\
\hline $\mathrm{F}$ & 51 & 33 & 1.16 & 7.27 & 8.64 & 7 & 35 & 50 & \multirow{3}{*}{$\begin{array}{l}\text { Stimulation for } \\
\text { apnoea } \\
\text { Stimulation for } \\
\text { bradycardia } \\
\text { Stimulation and } \\
\text { suction for } \\
\text { bradycardia and } \\
\text { desaturation }\end{array}$} \\
\hline $\mathrm{F}$ & 26 & 30 & 0.87 & 7.24 & 8.07 & 7 & 42 & 38 & \\
\hline M & 5 & 29 & 1.09 & 7.34 & 5.45 & 6 & 21 & 45 & \\
\hline
\end{tabular}

Table 3 Emergency referrals intubated and ventilated before transfer

\begin{tabular}{|c|c|c|c|c|c|c|c|c|}
\hline Sex & $\begin{array}{l}\text { Postnatal } \\
\text { age } \\
\text { (days) }\end{array}$ & $\begin{array}{l}\text { Corrected } \\
\text { gestation } \\
\text { (weeks) }\end{array}$ & $\begin{array}{l}\text { Current } \\
\text { weight } \\
\text { (kg) }\end{array}$ & Working diagnoses & $\begin{array}{l}\text { Arterial } \\
\mathrm{pH} \text { at } \\
\text { referral }\end{array}$ & $\begin{array}{l}\text { Arterial } \\
\mathrm{PaCO}_{2} \text { at } \\
\text { referral }\end{array}$ & $\begin{array}{l}\text { CPAP } \\
\left(\mathrm{cm} \mathrm{H} \mathrm{H}_{2} \mathrm{O}\right)\end{array}$ & $\begin{array}{l}\mathrm{F}_{1} \mathrm{O}_{2} \\
\text { at referral }\end{array}$ \\
\hline $\mathrm{F}$ & 95 & 48 & 3.12 & $\begin{array}{l}\text { Cardiac failure, } \\
\text { congenital heart disease }\end{array}$ & 7.4 & 7.1 & 7 & 80 \\
\hline M & 0 & $28^{+5}$ & 1.03 & $\begin{array}{l}\text { Prematurity, respiratory } \\
\text { distress syndrome }\end{array}$ & 7.13 & 10.1 & 5 & 40 \\
\hline
\end{tabular}

$\mathrm{CPAP}$, continuous positive airway pressure; $\mathrm{PaCO}_{2}$, arterial carbon dioxide tension; $\mathrm{FlO}_{2}$, fractional inspired oxygen.

55 referrals accepted, 27 were subsequently cancelled by their referring units. Eleven infants were transferred with no respiratory support or receiving supplementary oxygen from nasal cannulae. Clinical deterioration was identified on review of one infant. This infant with congenital heart disease required intubation and ventilation by medical staff in the referring unit before safe transfer by a doctor/nurse team.

Sixteen infants receiving nasal CPAP were transported by the nurse led team (table 4).

The mean (SE) duration of the journey was 60.3 (5.8) minutes (range 25-115). Intervention during transport was required in two of these cases. One infant required stimulation for apnoea with associated bradycardia. One infant required repositioning of nasal prongs with no associated change in clinical state. There was no equipment malfunction, and sufficient medical gases were always available.

\section{DISCUSSION}

Infants requiring nasal CPAP make up a small but significant proportion of our work load. One hundred such infants were transferred successfully without any adverse consequences, using standard equipment.

Transfers of infants while receiving nasal CPAP have been carried out in the East of England for some time. It is safe to assume that such transfers also occur in other parts of the country. Unfortunately no data exist on the extent and safety of this practice. Developing clinical networks and the availability of centralised dedicated neonatal transport services are likely to result in a greater number of infant transfers. Many of these infants will be repatriated to their local hospitals at an earlier stage, some still requiring nasal CPAP support. This is borne out by the fact that 73 of these transfers were carried out either as repatriations or to release capacity at one of the tertiary units in the region.

Table 4 Characteristics of infants, transferred by the nurse led team, who received nasal continuous positive airway pressure during transfer

\begin{tabular}{lllll}
\hline Sex & $\begin{array}{l}\text { Postnatal } \\
\text { age (days) }\end{array}$ & $\begin{array}{l}\text { Completed } \\
\text { weeks of } \\
\text { gestation }\end{array}$ & $\begin{array}{l}\text { Current } \\
\text { weight }\end{array}$ & $\begin{array}{l}\text { Ing) } \\
\text { during } \\
\text { transport }\end{array}$ \\
\hline$M$ & 28 & 32 & 1.5 & Nil \\
$M$ & 77 & 39 & 1.9 & Nil \\
$M$ & 15 & 31 & 2.8 & Nil \\
$M$ & 77 & 39 & 1.9 & Nil \\
$M$ & 23 & 30 & 1.1 & Nil \\
$M$ & 11 & 32 & 1.0 & Nil \\
$M$ & 56 & 38 & 2.7 & Prongs repositioned \\
$M$ & 55 & 33 & 1.3 & Nil \\
$M$ & 34 & 31 & 1.1 & Nil \\
$F$ & 45 & 32 & 1.2 & Nil \\
$M$ & 70 & 34 & 2.5 & Nil \\
$F$ & 96 & 37 & 1.7 & Nil \\
$F$ & 13 & 33 & 1.7 & Nil \\
\hline$F$ & 10 & 31 & 1.4 & \\
M & 96 & 37 & 1.7 & \\
$M$ & 22 & 31 & 1.0 & \\
\hline
\end{tabular}




\section{What is already known on this topic}

- Nasal CPAP is an effective method of respiratory support in neonatal intensive care

- It is technically feasible to use CPAP during land based transport of newborn infants, but there are limited data on its safety and effectiveness

As a service responsible for such transfers, we have attempted to develop an approach of carefully selecting infants who may be safely transferred while receiving nasal CPAP. This approach has resulted in minimal levels of intervention during transport, and to date, even with our growing experience, remains unchanged. Selection of suitable infants is a several stage process and is dependent on clear and frequent communication between the referring and receiving units and the transport team.

Careful selection of infants is all the more important for the nurse led transfers. The central location of most transport services means that their staff are not able to personally assess the infant before accepting the transfer and therefore have to rely on information provided by the referring hospital. Our transport nurses have accumulated considerable experience in neonatal transport. During the study period, the average number of transfers led by individual nurses was 51 . This is in addition to the transfers undertaken by them when part of the emergency team.

We have opted not to use a stand alone system such as the Infant Flow Driver (Electro Medical Equipment Ltd, Brighton, Sussex, UK ), relying instead on the integral ventilator with which our staff are familiar. Although there are data suggesting some benefits in using the Infant Flow Driver over conventional infant ventilators ${ }^{10}$ during hospital intensive care, in our opinion the additional weight and the staff training problems associated with its use could not be justified in the absence of data indicating its superiority during short term transport. The gases used during transport were neither warmed nor humidified. Safe delivery of warm humidified gases during transport remains a major challenge. Apart from local solutions with the help of hospitals' own medical physics departments, there is no device currently available that can efficiently resolve this problem. Compatible heat moisture exchangers are available for the Babylog 2000, but there are no published data on their efficacy during transport. Although this is an important problem which should be addressed, our short term data have shown no adverse effects from the lack of this facility.

In our experience there is a demand for transferring infants receiving nasal CPAP. Nasal CPAP appears to be a safe method of respiratory support for a carefully selected group

\section{What this study adds}

- Nasal CPAP can be a safe mode of respiratory support during land based transport of newborn infants

- There is a demand for this practice, but infants should be selected carefully for such transfers with senior advice available at all times

of infants during land based ambulance transfers carried out by experienced staff. Some initial criteria help with patient selection. Clear lines of communication and senior advice should be available at all times. It is feasible to transfer these infants by using existing equipment with which staff are familiar. There is a need for more research to further develop criteria for selecting infants who are suitable for transfer while receiving nasal CPAP. Until then such transfers should be undertaken by suitable teams, and all the resources should be available for increasing the level of respiratory support if required.

\section{Authors' affiliations}

R K Bomont, I U Cheema, Acute Neonatal Transport Service, Addenbrookes Hospital, Cambridge, UK

Competing interests: none declared

\section{REFERENCES}

1 Gregory GA, Kitterman JA, Phibbs RH, et al. Treatment of the idiopathic respiratory-distress syndrome with continuous positive airway pressure. N Engl J Med 1971;284:1333-40.

2 Morley C. Continuous distending pressure. Arch Dis Child Fetal Neonatal Ed 1999;81:F152-6.

3 Donoghue D, the ANZNN. The report of the Australian and New Zealand Neonatal Network, 2000. Sydney: ANZNN, 2002.

4 Kosowsky JM, Gasaway MD, Stephanides SL, et al. EMS transports for difficulty breathing: is there a potential role for CPAP in the prehospital setting? Acad Emerg Med 2000;7:1165.

5 Fenton AC, Leslie A, Skeoch CH. Optimising neonatal transfer. Arch Dis Child Fetal Neonatal Ed 2004;89:F215-19.

6 Simpson JH, Ahmed I, McLaren J, et al. Use of nasal continuous positive airway pressure during neonatal transfer. Arch Dis Child Fetal Neonatal Ed 2004;89:F374-5.

7 Department of Health. Neonatal intensive care review: strategy for improvement. Report of the Neonatal Intensive Care Services Review Group. London: DOH, 2003.

8 Gill AB, Bottomley L, Chatfield S, et al. Perinatal transport: problems in neonatal intensive care capacity. Arch Dis Child Fetal Neonatal Ed 2004;89:F220-3.

9 British Association of Perinatal Medicine. Standards for hospitals providing neonatal intensive and high dependency care. 2nd ed. London: BAPM.

10 Mazzella M, Bellini C, Calevo MG, et al. A randomised control study comparing the Infant Flow Driver with nasal continuous positive airway pressure in preterm infants. Arch Dis Child Fetal Neonatal Ed 2001;85:F86-90. 